College believes it is essential for nurses who wish to take up higher appointments to be so prepared. Courses provided by the College include a two-year course in preparation for the Sister Tutor Diploma of the University of London and a course for the Health Visitor Certificate of the Royal Society of Health. The College also awards its own certificates on successful completion of courses given for nurse administrators and teachers, for ward and departmental sisters, and for occupational health nurses. Refresher courses and study conferences are also arranged.

The Scottish Board of the College and its Committee for Northern Ireland also arrange post-registration courses and the Birmingham Centre of Nursing Education provides refresher courses for students in that area.

The respective functions of the two bodies with major responsibility for nursing education was given in greater detail in the British Medical Journal of September 7, 1957 (p. 586).

\section{Medical Auxiliaries}

The Board of Registration of Medical Auxiliaries (B.M.A. House, Tavistock Square, London, W.C.1) exists to maintain and publish a register of properly qualified medical auxiliaries. The Board helps the medical auxiliary professions to attain or to consolidate and improve their professional status, and insists that each such profession shall, before registration, establish at least the basic principles for training and practice. In return it offers the registered persons protection in that they and they only are recommended to doctors as qualified to practise their particular specialty.

Separate or sectional registers of members of each branch of medical auxiliary work are printed, and are supplied free to medical officers of health, hospital management committees, hospitals, executive councils, public libraries, medical practitioners, and others, the circulation lists varying according to the particular group of auxiliaries.

The register is composed of the following sections: audiology technicians, chiropodists, dispensing opticians, operating theatre technicians, orthoptists, radiographers, and venereal disease technicians. Copies of any or all of the current sections will be sent free to medical practitioners on application to the registrar.

The Chartered Society of Physiotherapy (Tavistock House South, Tavistock Square, London, W.C.1) approves 34 schools, connected with hospitals in London and the Provinces. These schools prepare students for the Society's examinations, which are recognized by the Ministry of Health under the National Health Service (Medical Auxiliaries) Regulations, 1954. Successful candidates may practise as Chartered Physiotherapists.

The Trading Representations (Disabled Persons) Act received the Royal Assent on July 23. Its purpose is to control the attempts of certain traders to exploit the sympathy and good will which is generally felt for blind and other disabled people by making misleading and exaggerated claims about the extent to which their business provides employment for, or otherwise benefits, such people. It applies only to representations made in the course of postal or house-to-house canvassing, since it is these particular forms of trading which are thought to have given rise to abuse. The effect of the Act is that after January 1, 1959, it will be a punishable offence to make the kind of representations referred to in the Act unless the person carrying on the business has his name included in a register to be set up by the Minister of Labour and National Service. This provision will not apply where the business is carried on by a local authority, by a non-profit-making body, or by a disabled person selling his own products. Any person guilty of an offence under the Act will be liable on summary conviction to a fine not exceeding $£ 100$ or imprisonment for a term not exceeding three months, or both.

\section{To-day's Drugs}

In this column we publish from time to time authoritative notes on a selection of drugs in current use.

Codelprone (Merck Sharp and Dohme Ltd.).-Each tablet of this substance contains prednisolone $2 \mathrm{mg}$., meprobamate $200 \mathrm{mg}$., and dried aluminium hydroxide $200 \mathrm{mg}$. The rationale of this mixture is that the calming effect and spasmolytic action of meprobamate and the buffering action of the antacid are added to the anti-inflammatory action of the steroid. It is therefore put out for use in all those conditions for which prednisolone is at present prescribed; its indications and contraindications are those of prednisolone. The dosage recommended is the lowest which keeps the symptoms adequately controlled; an initial dosage of 2 tablets three or four times a day is suggested.

N.H.S. basic price: 100 tabs., 72 s.

Bemaco (B. M. Laboratories Ltd.).-The composition of these tablets is: chloroquine phosphate $42 \mathrm{mg}$., acetylsalicylic acid $162.5 \mathrm{mg}$., calcium carbonate $45 \mathrm{mg}$., ascorbic acid $25 \mathrm{mg}$., and citric acid $15 \mathrm{mg}$. The rationale here is that the action of chloroquine potentiates that of acetylsalicylic acid, and for this reason its use is advocated in rheumatoid arthritis and allied arthropathies in a dose of 6 to 12 tablets a day. But chloroquine can hardly as yet be said to have been accepted by most clinicians as of proved use in rheumatoid arthritis.

N.H.S. basic price: 100 tabs., 10 s.

Chloromycetin Palmitate Suspension (Parke, Davis and Co.).-Chloramphenicol (chloromycetin) palmitate has not the bitter taste of chloramphenicol. The palatability of this suspension thus enables the antibiotic to be given without difficulty to children who cannot swallow capsules. This compound is broken down in the bowel, and the chloramphenicol so liberated is absorbed, exerting the same action as if it had been administered as such.

Chloramphenicol is superior to any other antibiotic for the treatment of typhoid and paratyphoid fever and of severe cases of salmonella gastro-enteritis ; for some forms of meningitis, particularly those due to coliform bacilli or $H$. influenzae, both because of the sensitivity of these species and because chloramphenicol attains higher concentrations in the cerebrospinal fluid than other antibiotics; and for infections of the air passages due to $H$. influenzae. It is also valuable, although its superiority to other drugs has perhaps not been so clearly proved, in acute laryngotracheo-bronchitis, whooping-cough, and the virus pneumonias. As a broad-spectrum antibiotic it has many other possible uses for which other drugs are as good or better.

Whether this distinction between indications for which there are or are not equivalent alternatives is important depends on the view taken about the risk of producing aplasia of the bone marrow. The frequency of this complication is much disputed. A recent author reports 7 cases seen in one city within a year, while others have used the drug freely without ever encountering it. No second factor contributing to it is known. The risk is probably greater when large doses are given or treatment is prolonged, although quite small doses have also had the same effect. It is probably unwise to continue a course for much more than a week, but this should rarely be necessary.

N.H.S. basic price: $60 \mathrm{ml} ., 10 \mathrm{~s} .8 \mathrm{~d}$.

Correction.-We regret that the N.H.S. basic prices for "nilergex" tablets were given incorrectly (August 23, p. 507); they should be : 100 4-mg. tabs., 18s. 4d.; 100 12-mg. tabs., 33s. 4d. 